recebido várias ofertas de instituições estrangeiras). Neste sentido, deixamos aqui o nosso convite a todos os responsáveis por projectos de investigação e aos gabinetes de recursos humanos de todas as Universidades e empresas privadas para nos enviarem toda a informação acerca da bolsa ou emprego que pretendam publicitar. Contamos com a vossa adesão para o crescimento desta plataforma!

ChemRUS - Este espaço pretende afirmar-se como uma biblioteca on-line de experiências de Química, compostas por um vídeo com a execução experimental e uma ficha científica contendo uma breve descrição dos conceitos químicos, protocolo experimental detalhado e procedimentos de segurança tidos em conta durante a sua realização. Para a dinamização desta secção, o GQJ propõe o envolvimento activo das Escolas de Ensino Secundário, através da participação na primeira edição do concurso ChemRUS.

Durante o ano lectivo 2010/2011 lançamos o desafio a todos os alunos e professores de Química do Ensino Secundário a participarem, enviando um vídeo e respectiva ficha científica acerca da realização de uma experiência Química escolhida por cada grupo. As Escolas Secundárias interessadas em participar deverão inscrever-se por e-mail até 31 de Março de 2011; o prazo para o envio dos vídeos termina a 31 de Maio de 2011. A Escola vencedora será anunciada durante o mês de Junho de 2011, e será premia- da com material didáctico/laboratorial que certamente ajudará ao ensino da Química.

Para mais informações acerca das actividades aqui descritas e de outras actividades do GQJ, poderá ser consultada a página web do Grupo: www. spq.pt/gqj. Teremos também todo o prazer em responder a qualquer comentário, dúvida ou sugestão, que poderão ser enviados para o e-mail geral gqjovens@spq.pt.

Contamos com a vossa participação e desejamos a todos um óptimo Ano Internacional da Química!!

\section{VC, SS, MS}

(GQJ)

\title{
Prémio Ferreira da Silva 2010 e Medalha Vicente de Seabra 2010
}

Presidido e nomeado pelo Presidente da SPQ, de acordo com o Regulamento, o júri constituído para a avaliação das candidaturas reuniu em Lisboa, na sede, em 27 de Outubro, tendo decidido por unanimidade atribuir o Prémio Ferreira da Silva 2010 ao Prof. Fernando Jorge da Silva Pina, Professor
Catedrático da Faculdade de Ciências e Tecnologia da Universidade Nova de Lisboa (Campus de Monte de Caparica). Decidiu ainda atribuir ex-aequo a Medalha Vicente de Seabra ao Prof. Eurico José da Silva Cabrita, Professor Auxiliar da Faculdade de Ciências e Tecnologia da Universidade Nova de Lisboa (Campus de Monte de Caparica) e ao Dr. José Richard Baptista Gomes, Investigador Auxiliar do $\mathrm{Cl}$ CECO da Universidade de Aveiro. Os premiados proferirão conferências no próximo Encontro Nacional da SPQ, a realizar em Braga em 2011.

MNBS

\section{Evolução do Número de Alunos Matriculados em Cursos de Química, 1997-2010}

$\mathrm{Na} 1^{\mathrm{a}}$ fase de acesso ao ensino superior de 2010, os cursos de licenciatura e mestrado com a designação de "Química" (Ensino de Física e Química, Bioquímica, Engenharia Química e Química (inclui Química Aplicada, Química Industrial e Química Tecnológica)) preencheram 1224 vagas das 1400 disponíveis, o que representa um aumento de cerca de $3.8 \%$ no número de alunos relativamente ao ano anterior.

A Figura 1 ilustra a evolução do número de candidatos colocados em $1^{\text {a }}$ fase e do número de matriculados pela primeira vez no $1^{\circ}$ ano a 31 de Dezembro de cada ano, desde 1997, em cursos com designação de "Química": Ensino de Física e Química, Bioquímica, Engenharia Química e Química (inclui Química Aplicada, Química Industrial, Química Tecnológica, etc). Depois do período de acentuado declínio do número de alunos que se verificou no início da década, os últimos 5 anos representam um período de recuperação sustentada, que aponta para a estabilização do número de alunos próximo dos 1500 a nível nacional.

Embora o conjunto de explicações possíveis para esta recuperação do número de alunos nos cursos de Química seja vasto, não pode deixar de ser aqui salientado que o período de recuperação coincide com o Programa "Atracção Química", lançado em 2004 pela SPQ - em colaboração com os Departamentos de Química das Universidades Portuguesas -, "com o objectivo de despertar o interesse pela Química entre os jovens e cativar vocações para carreiras no âmbito da Química". Se outro mérito não teve - e não foi possível efectuar uma avaliação detalhada dos efeitos deste programa - o "Atracção Química" terá tido o mérito de alertar os Departamentos de Química para a possibilidade/necessidade de se promoverem junto dos futuros alunos e da sociedade em geral, valorizando o esforço daqueles que se dedicavam às chamadas "actividades de divulgação".

Mais significativa é a análise da evolução do número de alunos matriculados nos diferentes cursos, apresentada graficamente na Figura 2. Os valores para 2010 foram obtidos por estimativa, com base no número de candidatos colocados em $1^{\text {a }}$ fase.

Nesta figura é evidente o decréscimo acentuado do número de alunos inscritos em Engenharia Química até 2006 - o que foi acompanhado do 